\section{NEURO-ONCOLOGY FELLOWSHIP}

A clinical fellowship in neuro-oncology is available for neurologists and neurosurgeons. The program offers comprehensive training in the diagnosis and management of primary brain tumor, neurological complications of cancer and pain due to cancer. A second research year will be encouraged.

Please submit curriculum vitae and three letters of reference to:

J. Gregory Cairncross, M.D.

The London Regional Cancer Centre 391 South Street

London, Ontario

N6A 4G5

Canada

\section{ADVERTISER'S INDEX}

Dantec Electromedical

Neuromatic - viii

Evomatic - v

"New Dimensions" - $\mathrm{xv}$

Sandoz

Parlodel - ii, iv

Cafergot - IFC

Parke Davis Canada

Dilantin - vi, IBC

DuPont Pharmaceuticals

Symmetril - vii

Unimed

Serc - iii

Ciba Geigy

Lioresal $-\mathrm{x}, \mathrm{xi}$, xii

Tegretol - OBC, $x i$

Hoffman La Roche

Prolopa - xiv, xiii

\section{CLASSIFIED ADS:}

The London Regional Cancer Centre - xvii

Trail Regional Hospital

CanMed Careers

\section{TRAIL REGIONAL HOSPITAL Trail, British Columbia invites applications for NEUROLOGIST}

A neurologist is required for a 228 bed regional hospital located in Trail, British Columbia, Canada. This is a regional hospital with a medical staff of 48 . Service area for neurologist is approximately 75,000 population with services for angiography, nuclear medicine, ultrasound, and EEG. CAT scan has been approved for 1987.

Trail is located in the southeastern corner of British Columbia in the Kootenays and offers superb recreational and educational facilities.

\section{Dr. K.B. LeRose}

Recruitment Committee

Trail Regional Hospital

Trail, B.C. V1R 4M1

Telephone: (604) 368-3311

\title{
NEUROLOGIST
}

Neurologist required for a community of approximately 125,000 in South Western Ontario.

An excellent opportunity exists to develop a busy practice strongly supported by the local medical community.

FRCP(C), Neurology; License or eligibility for licensure in Ontario.

\section{FOR FURTHER INFORMATION (REF. \#87019)} PLEASE CONTACT:

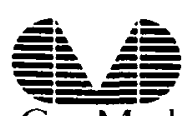

CanMed
CanMed Careers

659 Mississauga Crescent Mississauga, Ontario L5H 129

Telephone: (416) 274-0707

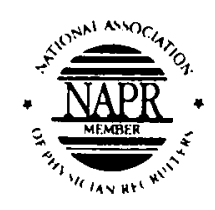

INTERNATIONAL CONSULTANTS TO EXECUTIVES AND PROFESSIONALS IN THE HEALTH CARE SECTOR 


\section{ANOTHER UNE VENTTUL DAY.}

\section{DILANTIN \\ (oheny $(0 \mathrm{in})$}

\section{Start with it. Stay with it.}

DILANTIN* (phenytoin) is a drug of first choice for controlling generalized tonic clonic seizures.

No other antiepileptic is more widely prescribed.

No other antiepileptic has been the subject of more extensive clinical studies?
And no other antiepileptic boasts a more simplified medication schedule. The slow absorption of Dilantin Capsules allows a single daily dose for maintenance therapy in many adults, once the divided dose of three $100 \mathrm{mg}$ capsules has adequately controlled seizures.

\section{PARKE-DAYSS \\ Parke-Davis Canada lnc. Scarborough, Ontario}

\section{PAAB}

-Reg. TM Parke, Davis 8 Company, Parke-Davis Canada lnc, auth. user 


\section{New Tegretol

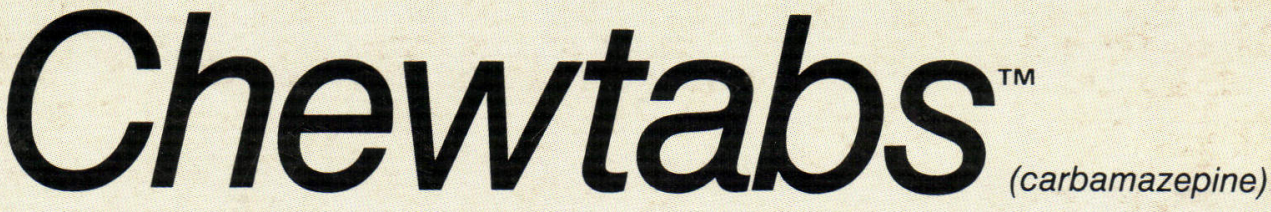

$\square$ the only chewable $100 \mathrm{mg}_{\text {and }} 200 \mathrm{mg}^{*}$ carbamazepine

$\square$ easier titration for both children and adults

$\square$ increased convenience provided by an easily administered chewable formulation

$\square$ improved compliance arising from a pleasant tasting cherry-mint flavour

Now indicated in children aged 6 years and over
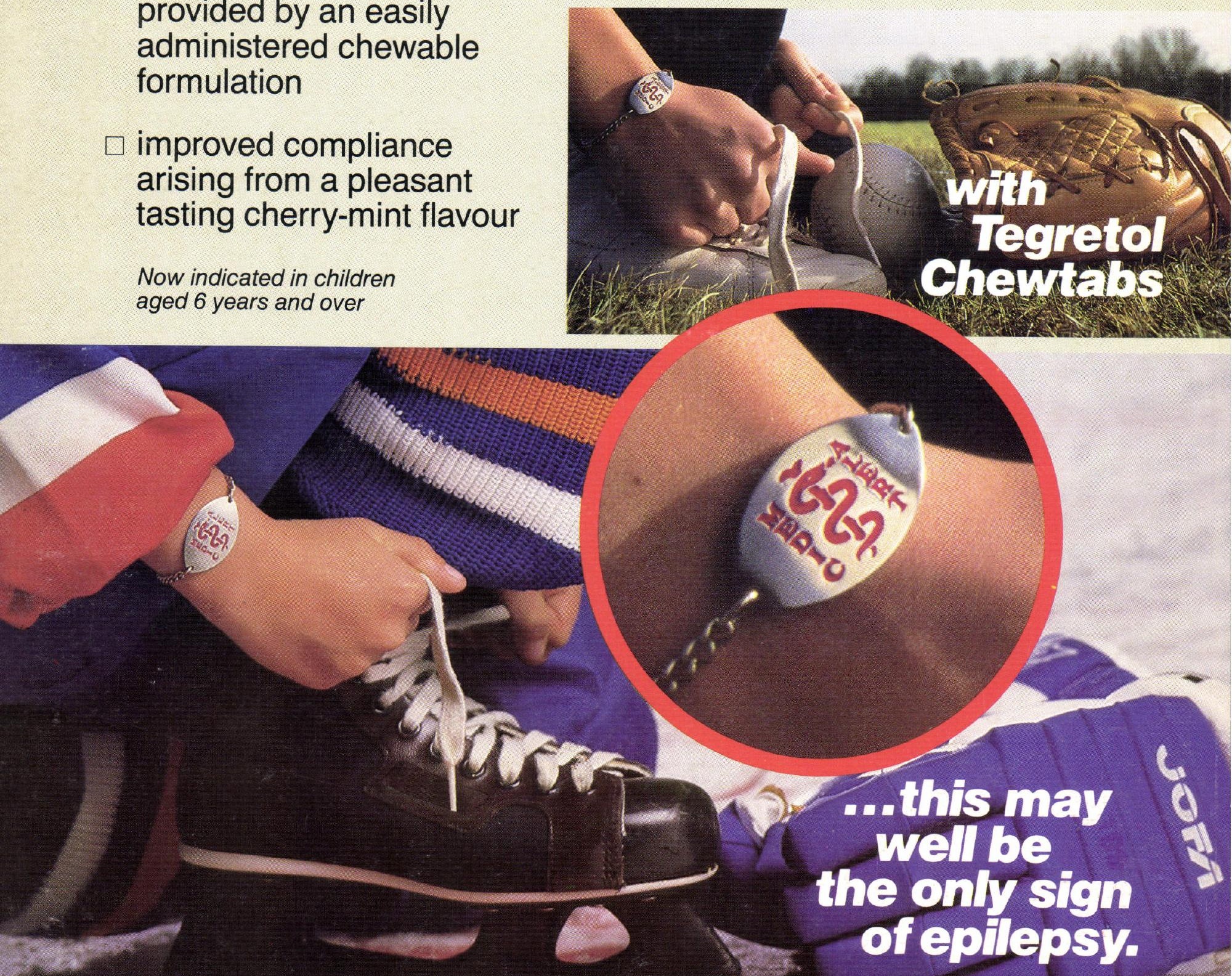